\title{
Pirina'nın Bitümün Fiziksel ve Mikroyapısal Özellikleri Üzerindeki Etkisi
}

\section{Effect of Pirina on the Physical and Microstructural Properties of Bitumen}

\author{
Tacettin Geçkil 1(), Ceren Beyza İnce ${ }^{2 *}$, Semih İssi 3 (1) \\ 1 İnönü Üniversitesi Mühendislik Fakültesi İnşaat Mühendisliği Bölümü, Malatya, TÜRKIYE \\ 2,3 İnönü Üniversitesi Mühendislik Fakültesi İnşaat Mühendisliği Bölümü, Malatya, TÜRKIYYE \\ Sorumlu Yazar / Corresponding Author*: c.beyzaince@gmail.com \\ Geliş Tarihi / Received: 07.01.2021 \\ Araştırma Makalesi/Research Article \\ Kabul Tarihi / Accepted: 12.05.2021 \\ DOI:10.21205/deufmd.2021236927 \\ Atıfșekli/How to cite: GEÇKIL T., INCE C.B., ISSI S.(2021). Pirina'nın Bitümün Fiziksel ve Mikroyapısal Özellikleri Üzerindeki Etkisi. DEÜFMD \\ 23(69), 1015-1025.
}

Öz

$\mathrm{Bu}$ çalışmada, biyokütlesel bir atık olan pirina'nın bitümün fiziksel ve mikroyapısal özellikleri üzerindeki etkisi araştırılmıştır. Bu amaçla, B 160/220 penetrasyon sınıfı saf bitüme, ağırlıkça \%5, $\% 10, \% 15$ ve $\% 20$ oranlarında pirina ilave edilerek modifiye bitümler elde edilmiștir. Saf ve modifiye bitümlerin fiziksel özellikleri penetrasyon, yumuşama noktası ve düktilite testleri ile belirlenerek sıcaklık hassasiyetleri de tespit edilmiștir. Bağlayıcıların yaşlanma eğilimi veya yüksek sıcaklık ve oksidasyona karşı direnci ise dönel ince film etüvü deneyi (RTFOT) ile belirlenmiştir. Ayrıca, pirina'nın bitümün yapısında meydana getirmiş olduğu mikroyapısal değişimler ise taramalı elektron mikroskobu (SEM) ve X-ıșını kırınımı (XRD) analizleri ile belirlenmiștir. Elde edilen sonuçlara göre, pirina ilavesiyle bağlayıcıların \%15 oranına kadar sertleșme eğiliminin arttığı, daha sonra azaldığı, ayrıca pirina katkısıyla bağlayıcıların bitüm sınıfının değiștiği görülmüştür. Ayrıca, pirina katkısıyla bağlayıcıların sıcaklık hassasiyetlerinin düștüğü ve dolayısıyla yüksek sıcaklığa sahip bölgelerde kalıcı deformasyonlara karşı kullanılabileceği tespit edilmiştir. RTFOT sonuçlarına göre, pirina katkısının bağlayıcıların yüksek sıcaklık ve oksidasyona karșı direncini arttırdığı belirlenmiștir. SEM ve XRD kimyasal analiz sonuçlarına göre ise, pirinanın bitüm içerisinde homojen olarak dağıldığı ve karışımı tek fazlı bir yapı haline getirdiği görülmüştür.

Anahtar Kelimeler: Bitüm, Pirina, Modifiye Bitüm, Fiziksel Özellik, SEM, XRD.

\begin{abstract}
In this study, the effect of pirina, a biomass waste, on the physical and microstructural properties of bitumen were investigated. For this purpose, modified bitumens were obtained by adding B 160/220 penetration grade pure bitumen to $5 \%, 10 \%, 15 \%$ and $20 \%$ of pirina by weight. The physical properties of pure and modified bitumens were determined by penetration, softening point and ductility tests, and their temperature sensitivity was also determined. The aging tendency of the binders or their resistance to high temperature and oxidation was determined by the rolling thin film oven test (RTFOT). In addition, microstructural changes caused by pirina in the structure of bitumen were determined by scanning electron microscopy (SEM) and X-ray diffraction (XRD) analysis. According to the results, it was observed that the tendency of the binders to harden up to $15 \%$ with
\end{abstract}


the addition of pirina, then decreased, and the bitumen class of the binders changed with the addition of pirina. In addition, it has been determined that the temperature sensitivity of the binders decreases with the pirina additive and therefore it can be used against permanent deformations in regions with high temperatures. According to the results of RTFOT, it was determined that pirina additive increased the resistance of binders against high temperature and oxidation. According to SEM and XRD chemical analysis results, it was seen that the pirina was homogeneously dispersed in the bitumen and the mixture became a single phase structure.

Keywords: Bitumen, Pirina, Modified Bitumen, Physical Property, SEM, XRD.

\section{Giriş}

Bitümlü sıcak karışımlar (BSK) kaplamalar, ağırlıkça \%5-7 oranındaki bitüm ile ağırlıkça \% 93-95 oranındaki agreganın belirli bir sıcaklıkta plentte karıştırılmasıyla elde edilmektedir. Karıșımda küçük bir oranda bulunan bitüm, agrega daneleri ile birleștiğinde onları birbirine bağlayarak, düzgün bir kaplama yüzeyi olușturur ve trafik yükleri altında kaplamanın dağılmasını önler. Ayrıca karışımın boşluklarını doldurarak geçirimsizliği ve iyi bir sürüş konforu sağlar [1-4].

Viskoelastik ve termoplastik bir malzeme olan bitüm sıcaklık, çevre koşulları, trafik yükleri ve yük şiddetine bağlı olarak kaplamanın farklı davranıșlar sergilemesine sebep olmaktadır [3, 5-7]. Bitümün bu farklı davranışları sebebiyle, BSK kaplamalarda hizmet ömrü içerisinde kalıcı deformasyon, düşük sıcaklık çatlakları ve yorulma çatlakları gibi bozulmalar meydana gelmektedir $[4,7,8]$.

Kaplamalarda meydana gelen bu bozulmaları en aza indirmek veya ortadan kaldırmak amacıyla çeşitli katkı malzemeleri kullanılarak bitümler modifiye edilmekte ve kaplamaların performansı arttırılmaya çalışılmaktadır. Katkı malzemelerinin bitüme eklenmesiyle elde edilen bitümlere modifiye bitümler denilmektedir [9]. Günümüzde modifikasyon için başta polimerler olmak üzere kauçuk, çeşitli yağlar, filler malzemeler, elyaflar ve çeşitli çözücüler gibi katkı malzemeleri kullanılmaktadır [3,9]. Ancak kullanılan bu katkı malzemelerinin, bir kısmının ekonomik olmaması veya istenen performansı tam olarak sağlayamaması sebebiyle, araștırmacılar son yıllarda bitüm modifikasyonunda atık malzemeleri kullanmaya başlamışlardır [5,10,11].

Atık malzemelerin önemli bir kısmı, enerji kaynağı olarak kullanılmakta olup biyokütle kaynağı olarak bilinmektedir. Dünya üzerinde hiç șüphesiz, doğal enerji kaynağı olarak kendini devaml yenileyebilecek enerji kaynağ biyokütlesel ürünlerdir [12-14]. Tarımsal ürün atıkları (bitkisel kalıntılar vb.), endüstriyel atıklar, ormansal atıklar (odun vb.), hayvansal atıklar (gübre vb.), gıda ișleme kalıntıları ve evsel atıklar çeșitli biyokütlesel kaynaklarıdır [15-18]. Biyokütlesel atıkların çeşitli alanlarda kullanılması konusunda son yıllarda çeșitli çalışmalar yapılmaktadır. Bu konuda yapılan çalıșmaların çoğu, bu atıkların geri dönüștürülerek kullanılması ya da yenilenebilir enerji üretiminde bir alternatif olarak değerlendirilmesi üzerine olmuştur [18].

Çeşitli kaynaklardan elde edilen biyokütle atıkları, termokimyasal ve biyolojik olmak üzere iki ana işlem sürecinden geçirilmektedir $[19,20]$. Termokimyasal süreçte, bu atıklar yanma, piroliz, gazlaștırma / Fischer- Tropsch sentezi ve biyokütlenin sıvılaştırılması şeklinde işlemlere tabi tutulmaktadır [21-23]. Biyokütlenin biyolojik olarak arıtılmasında ise sindirim, fermantasyon ve kompostlama işlemleri uygulanmaktadır [20]. Çoğunlukla kimyasal süreçlere tabi tutularak değerlendirilen biyokütle atıkları, çıkarmıs oldukları zararlı gazlar sebebiyle çevre dostu olmayıp ekolojiye zarar vermekte ayrıca kimyasal süreçte ikincil yardımcı kimyasallara ihtiyaç duyulması sebebiyle nispeten maliyetleri yüksek olmaktadır [24,25]. Bu nedenle, biyokütle atıklarının değerlendirilmesi için daha çevreci, daha düşük maliyetli ve sürdürülebilir çözümlere ihtiyaç vardır [25].

$\mathrm{Bu}$ çalıșmada ise, zeytinyağının üretimi așamasında elde edilen ve bir biyokütlesel ürün olan ham pirinanın bitümün fiziksel ve mikroyapısal özellikleri üzerindeki etkisi araştırılmıştır.

Pirina (zeytin posası), değerli bir tarımsal ürün olan zeytinyağının üretimi sonrasında oluşan, 
çekirdek, kabuk ve posadan meydana gelen bir yan üründür. Elde edildiği andan itibaren yaklaşı \%75-80 kuru madde, \%3-5 ham kül, $\% 35-50$ ham selüloz, \%5-10 ham protein ve \%815 ham yağ içeriğine sahiptir [26,27]. Ülkemiz, 91.700 .000 adet zeytin ağacl ve 1.800 .000 ton zeytin üretimi ile dünyada 4 . büyük zeytin üreticisidir $[27,28]$. Bu üretimin, yaklaşık \%75'i zeytinyağ zeytinyağı üretiminden de yaklaşık \%35-40 kadar pirina elde edilmektedir. $\mathrm{Bu}$ oranlar dikkate alınarak hesaplamalar yapıldığında ülkemizde yıllık olarak yaklaşık 472.500540.000 ton pirina elde edilmektedir. Elde edilen bu pirinanın az bir kısmı kışın hayvan yeminin zor bulunması sebebiyle kullanılsa da, büyük çoğunluğu atık olarak kalmakta ve çevreye zarar vermektedir [26,27].

Pirina malzemesinin kullanıldığı çalıșmalar incelendiğinde, bu malzemenin kimya araștırmacıları tarafından adsorban olarak kullanıldığı $[29,30]$, ziraat mühendisleri tarafından bu malzemenin biyodizel malzeme olarak kullanımının araștırıldığı [31], gıda mühendisleri tarafından ise kızartma yağı olarak kullanımının araştırıldığı görülmüştür [32]. Ancak, literatürdeki araștırmalar incelendiğinde bu malzemenin karayolu mühendisliğinde bir modifiyer olarak kullanımının hemen hemen araştırılmadığı görülmüştür. Yapılan tek çalışmada ise yanmış pirina kullanılarak bitüm modifikasyonu yapılmış ve pirinanın sıcak karıșımların nem direnci üzerindeki etkisi araştırılmıştır. Çalışma sonucunda, yanmış pirinanın bitümün sertleşmesinde etkili olduğu ve sıcak karıșımların nem direnci üzerinde olumlu bir etkiye sahip olduğu belirtilmiştir [33].

Bu çalıșmada, biyokütlesel bir tarımsal atık olan ve şuana kadar hiçbir çalışmada kullanılmayan ham pirina'nın bitümün fiziksel ve mikroyapısal özellikleri üzerindeki etkisi araştırılmıștır. Bu amaçla, saf ve modifiye bitümlerin fiziksel özellikleri penetrasyon, yumuşama noktası ve düktilite testleri ile; kısa dönem yaşlandırılması RTFOT ile; mikroyapısal özellikleri ise SEM ve XRD analizleri ile belirlenmiștir.

\section{Materyal ve Metot \\ 2.1. Materyal}

Bu çalışmada bitüm modifikasyonu için bağlayıcı olarak saf B 160/220 penetrasyon sınıfı bitüm (Şekil 1a), katkı malzemesi olarak zeytinyağının ișlenme prosesi sonucunda elde edilen ham pirina (Şekil 1b) kullanılmıştır.

Türkiye Petrol Rafinerileri A.Ș. (TUPRAȘ)'den temin edilen saf bitümün fiziksel özellikleri Tablo 1'de verilmiştir.

Modifikasyonda kullanılan ham pirina Kahramanmaraș zeytin fabrikasından temin edilmiştir. Pirina'nın genel özelikleri Tablo 2'de, element içeriği ise Tablo 3'de verilmiştir.
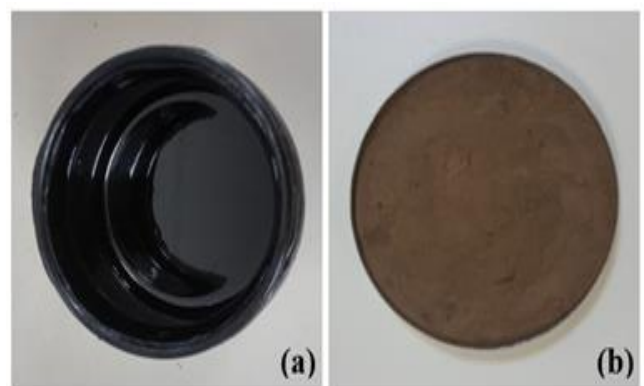

Şekil 1. B 160/220 saf bitüm (a); ham pirina (b)

Tablo 1. B 160/220 saf bitümün fiziksel özellikleri

\begin{tabular}{cccc}
\hline Özellik & Standart & Limitler & Sonuç \\
\hline Penetrasyon $(0.1 \mathrm{~mm})$ & ASTM D5 & $160-220$ & 163 \\
Yumuşama noktası $\left({ }^{\circ} \mathrm{C}\right)$ & ASTM D36 & $35-43$ & 41,6 \\
Düktilite $(\mathrm{cm})$ & ASTM D113 & min. 100 & $>100$ \\
Parlama noktası $\left({ }^{\circ} \mathrm{C}\right)$ & ASTM D92 & min. 220 & 244 \\
Özgül ağırlık $\left(\mathrm{gr} / \mathrm{cm}^{3}\right)$ & ASTM D70 & $1,0-1,1$ & 1,038 \\
Penetrasyon indeksi (PI) & - & - & $-0,27$ \\
\hline
\end{tabular}


DEÜ FMD 23(69), 1015-1025, 2021

Tablo 2. Pirina'nın genel özellikleri

\begin{tabular}{cc}
\hline Özellik & Sonuç \\
\hline Form & Ultra ince amorf toz \\
Koku & Kokusuz \\
Çözünürlük (suda) & Çözünmez/Hafifçe çözünür \\
Çözünürlük (organik çözücü) & Çözünmez $/ \mathrm{Az} \mathrm{çözünür}$ \\
Yoğunluk (gr $/ \mathrm{cm}^{3}$ ) & 1,9 \\
\hline
\end{tabular}

Tablo 3. Pirina'nın elementel analiz sonuçları

\begin{tabular}{cc}
\hline Özellik & Sonuç (\%) \\
\hline C & 48.10 \\
H & 6,37 \\
N & 1,515 \\
S & 0,087 \\
O* $^{*}$ & 43,928 \\
\hline
\end{tabular}

O*: CHNS'den geriye kalan olarak bulunmuștur.

\subsection{Metot}

\subsubsection{Modifiye Bitümlerin Hazırlanması}

Çalışmada, modifiye bitümler elde etmek amacıyla ilk olarak saf bitüm $150{ }^{\circ} \mathrm{C}$ sıcaklığa kadar ısıtıldı. Daha sonra bitüme ağırlıkça \%5, 10,15 ve 20 oranlarında pirina ilave edilerek, 1000 rpm hızında 60 dakika boyunca aynı sıcaklıkta karıștırma işlemi yapıldı ve modifiye bitümler hazırlandı. Modifikasyonda seçilen karıștırma koşulları, daha önce hazırlanmış olan deneme numunelerinin mikroyapısal özellikleri dikkate alınarak belirlenmiștir.

Elde edilen saf ve modifiye bitümlerin fiziksel özellikleri penetrasyon, yumuşama noktası ve düktilite testleri ile, kısa süreli yaşlandırılması ise dönel ince film halinde ısıtma kaybı deneyi (RTFOT) ile; bağlayıcıların kimyasal yapılarında meydana gelen değișimler ise SEM ve XRD karakterizasyon analizleri ile belirlenmiștir.

Çalışmada, saf ve modifiye bitümler sırasıyla $B$, $\mathrm{B}+\% 5 \mathrm{P}, \mathrm{B}+\% 10 \mathrm{P}, \mathrm{B}+\% 15 \mathrm{P}$ ve $\mathrm{B}+\% 20 \mathrm{P}$ olarak kodlanmiştır.

\section{Deneysel Yöntem}

\subsection{Geleneksel Bitüm Testleri}

Saf ve pirina katkılı bitümlerin fiziksel özellikleri ASTM D5, ASTM D36 ve ASTM D113 standartlarına göre sırasıyla penetrasyon (Şekil 2a), yumuşama noktası (Şekil 2b) ve düktilite (Şekil 2c) testleri ile belirlenmiştir.
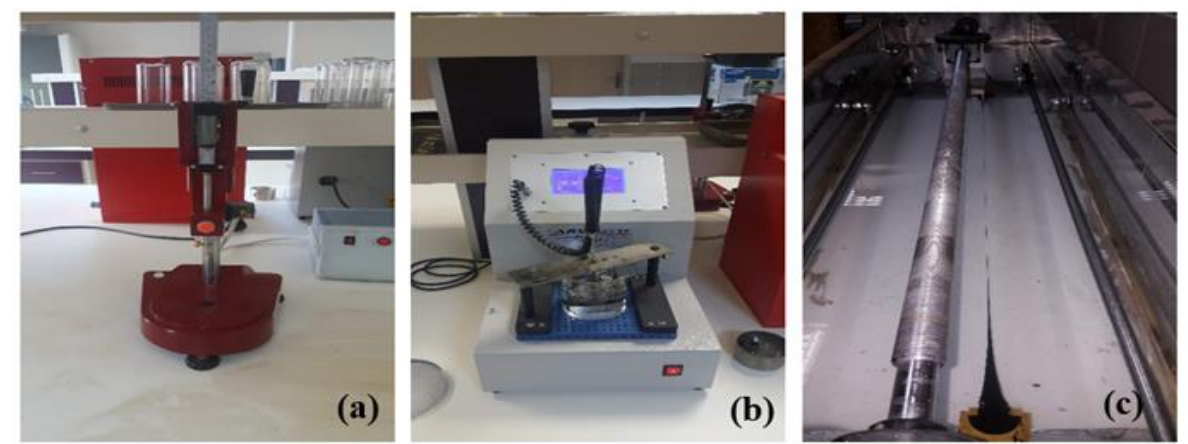

Şekil 2. Penetrasyon (a), yumuşama noktası (b), düktilite (c) cihazları

Ayrıca, bitümlerin sıcaklığa karşı değerleri de, bağlayıcıların penetrasyon ve hassasiyetlerinin bir parametresi olarak yumuşama noktası değerleri yardımı ile değerlendirilen penetrasyon indeksi (PI) denklem 1 kullanılarak hesaplanmıştır. 


$$
P I=\frac{1952-500 \times \log \left(\text { Pen }_{25}\right)-20 \times \mathrm{SP}}{50 \times \log \left(\text { Pen }_{25}\right)-\mathrm{SP}-120}
$$

Burada; Pen 25, $25{ }^{\circ} C^{\prime}$ deki penetrasyon değerini, $S P$ ise yumuşama noktası değerini ifade etmektedir. PI değerinin artması, bağlayıcının sıcaklık hassasiyetinin azaldığını ve sertliğinin arttığını göstermektedir. BSK'da, yüksek PI değerine sahip bir bitüm kullanıldığında, karışımların düşük sıcaklıklarda kırılmaya ve yüksek sıcaklıklarda kalıcı deformasyonlara karșı daha dirençli hale geldiği değerlendirilmektedir [3].
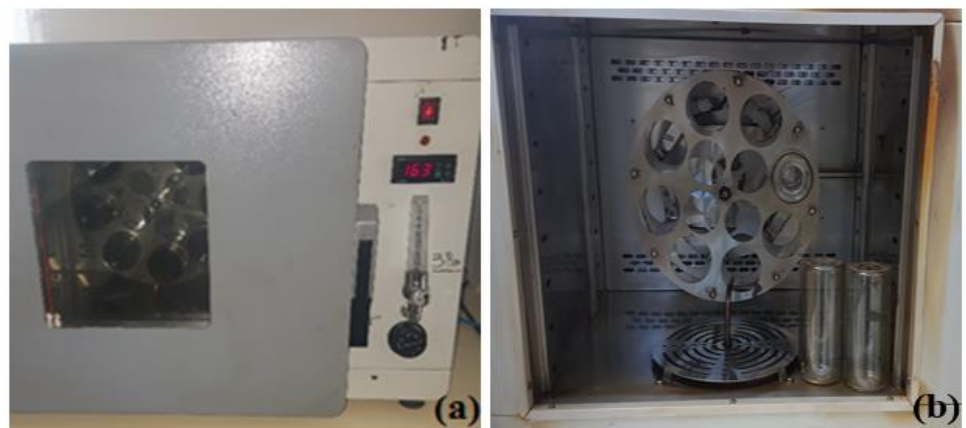

Şekil 3. RTFOT cihazı (a), kullanılan şişeler (b)

\subsection{Bağlayıcıların Mikroyapısal Analizleri}

Malzemelerin yüzey yapıları, dağılımları, gözenek boyutları ve fonksiyonel grupları gibi mikroyapısal özelliklerinin belirlenmesinde birçok kimyasal analiz yöntemi kullanılmaktadır [34-37]. Bitümlü bağlayıcıların mikroyapısal özelliklerinin tayin edilmesinde ise SEM ve XRD gibi kimyasal analizler çok sık kullanılmaktadır. Polimer modifiyeli bitümlerin (PMB) faz yapıları, bitüm-polimer uyumu SEM görüntüleri yardımıyla belirlenmektedir [34]. XRD,

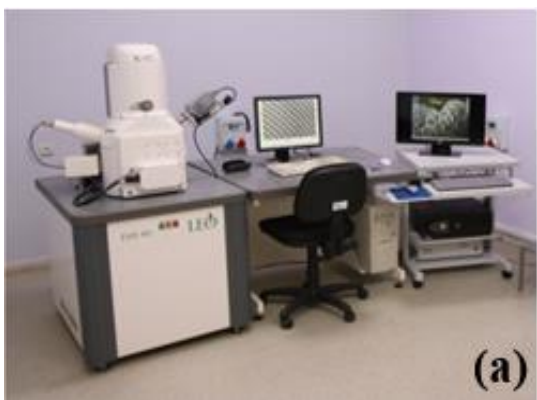

malzemelerin kristal fazlarını tanımlamak ve yapısal özelliklerini analiz etmek için kullanılan kimyasal bir analiz yöntemidir. Modifiye bitümlerin yapısal kristalit parametreleri XRD ile tespit edilmektedir [35].

Çalışmada, numunelerin SEM görüntüleri Zeiss EVO 50 (Şekil 4a) cihazı, XRD desenleri ise $\mathrm{CuK} \alpha$ radyasyonlu bir Rigaku Giegerflex D-Max / B toz difraktometre (Șekil 4b) cihazı kullanılarak elde edilmiștir.

Şekil 4. SEM (a) ve XRD (b) cihazları 


\section{Deneysel Sonuçlar}

\subsection{Geleneksel Bitüm Testleri Sonuçları}

Çalışmada, geleneksel bitüm testleri yardımı ile saf ve pirina katkılı bağlayıcıların fiziksel özellikleri belirlenmiştir. Ayrıca bağlayıcıların PI değerleri de hesaplanarak tüm sonuçlar Tablo 4'de verilmiştir. Bağlayıcıların fiziksel özelliklerinin pirina içeriklerine göre değişimi ise Şekil 5-7'de verilmiştir.

Tablo 4. Bağlayıcıların fiziksel test sonuçları

\begin{tabular}{cccccc}
\hline Deneyler & \multicolumn{5}{c}{ Bağlayıcı türleri } \\
\cline { 2 - 6 } & $\mathbf{B}$ & $\mathbf{B ~ + \% 5 P}$ & $\mathbf{B}+\% \mathbf{1 0 P}$ & $\mathbf{B}+\% 15 P$ & B +\%20P \\
\cline { 2 - 6 } Penetrasyon (0.1mm) & 163 & 152 & 142 & 120 & 130 \\
Yumuşama noktası $\left({ }^{\circ} \mathrm{C}\right)$ & 41,6 & 44,3 & 45,7 & 46,3 & 45,4 \\
Düktilite (cm) & 125 & 120 & 111 & 107 & 109 \\
PI & $-0,27$ & 0,45 & 0,66 & 0,23 & 0,22 \\
RTFOT sonrası & & & & & \\
Kütle kaybı (\%) & 0,47 & 0,26 & 0,18 & 0,13 & 0,10 \\
\hline
\end{tabular}

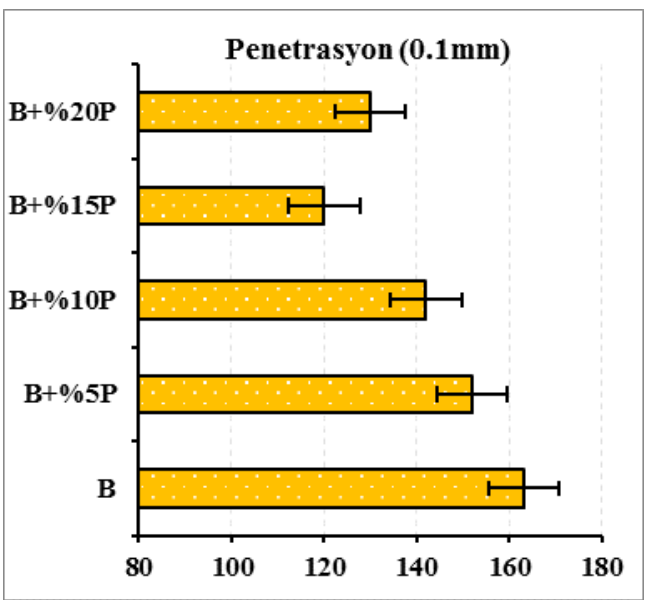

Şekil 5. Bağlayıcıların penetrasyon değișimleri

Şekil 5'de görüldüğü gibi, B 160/220 penetrasyon sinıflı saf bitüme pirina ilavesiyle $(\% 5,10,15$ ve 20$)$ penetrasyon değerleri saf bitüme kıyasla sırasıyla $\% 6,7 ; \% 12,9 ; \% 26,4$ ve $\% 20,2$ oranında azalma göstermiștir. Pirina ilavesiyle oluşan bu sertleşmenin doğal bir sonucu olarak, bağlayıcıların yumuşama noktası değerleri (Şekil 6) de saf bağlayıcıya kıyasla sırasıyla $\% 6,5 ; \% 9,9 ; \% 11,3$ ve $\% 9,1$ oranında artış göstermiştir. Bununla birlikte Şekil 7'de görüldüğü gibi, bağlayıcıların düktilite değerleri de saf bitüme kıyasla sırasıyla \%4; \%11,2; \%14,4 ve $\% 12,8$ azalma göstermiștir.

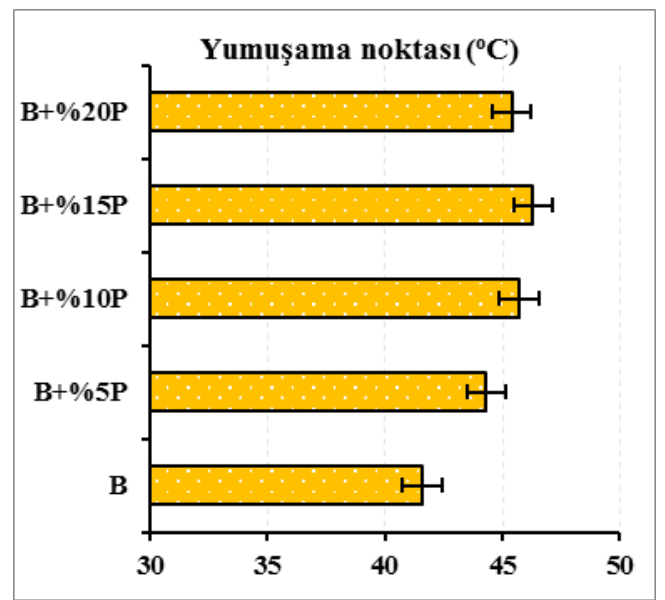

Şekil 6. Bağlayıcıların yumuşama noktası değișimleri

Ancak bu azalmalara rağmen, modifiye bağlayıcıların uzama yeteneğinde veya kohezyonunda bir olumsuzluk meydana gelmemiştir. Çünkü standardın saf bağlayıcılar için öngördüğü en az 100 mm uzama yeteneği modifiye bağlayıcılar için de sağlanmıștır. $\mathrm{Bu}$ sonuç, bağlayıcıların kohezyonu ve elastikiyeti üzerinde pirinanın olumlu bir etkiye sahip olduğunu göstermektedir. Bu orandan sonra (\%15), penetrasyon ve düktilitenin artış göstermesi, yumuşama noktası değerinin ise azalması özgül ağırlığı daha yüksek olan pirinanın karışımda dibe çökmesi sonucu 
meydana geldiğ değerlendirilmektedir.

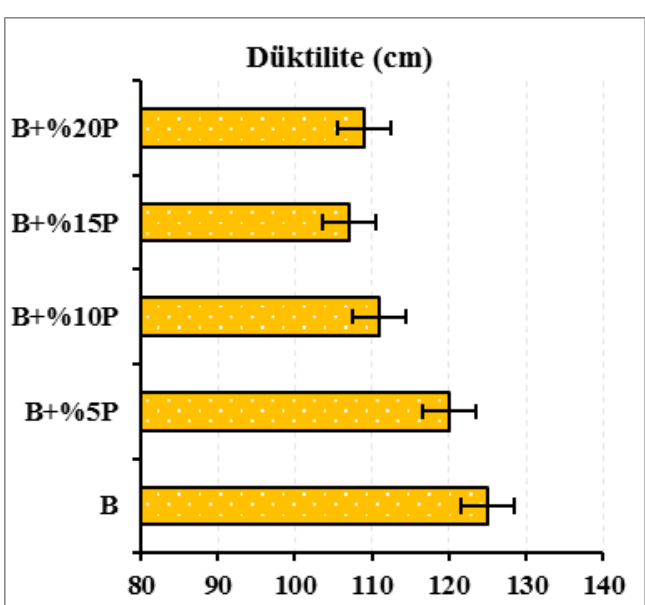

Şekil 7. Bağlayıcıların düktilite değişimleri

Fiziksel test sonuçlarına göre, pirina katkısı ile bağlayıcıların kıvamında sertleşme meydana geldiği ve bu sertleşme sonucunda bağlayıcıların daha sert kıvamlı B 100/150 penetrasyon sınıfı bitüme dönüștüğü tespit edilmiştir. Ancak bu sertleşme ile birlikte bağlayıcıların daha elastik bir katı gibi davrandığı [3] görülmüștür. $\mathrm{Bu}$ sebeple, pirina katkısı ile elde edilen bağlayıcıların daha sıcak bölgelerde kalıcı deformasyonlara karşı kullanılabileceği ifade edilebilir.

Katkı oranına bağlı olarak bağlayıcıların PI değerlerinde meydana gelen değișimler Şekil 8'de verilmiștir.

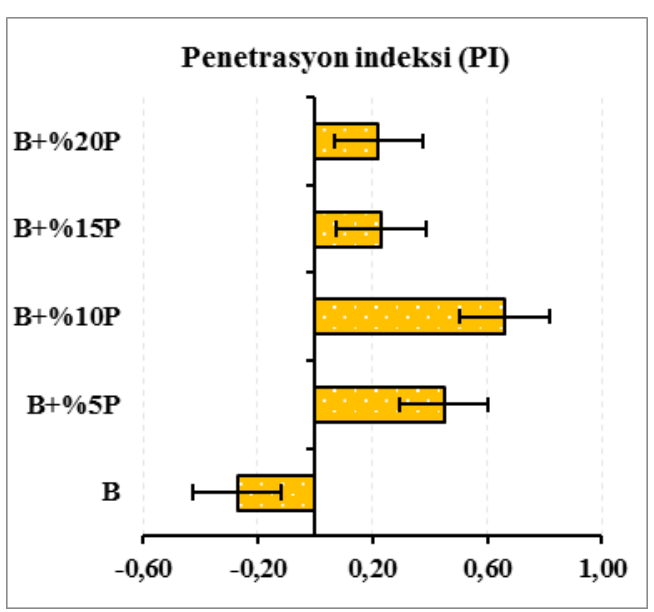

Şekil 8. Bağlayıcıların PI değișimleri
Şekil 8'de, saf bitüm ile kıyaslandığında pirina katkı miktarının artışına bağlı olarak bağlayıcıların PI değerlerinin artış gösterdiği görülmektedir. PI değerlerinde meydana gelen artış, özellikle \%10 pirina katkılı bağlayıcıların sıcaklık hassasiyetlerinin düşmesi sebebiyle özellikle kalıcı deformasyonlara karşı daha dirençli olacağını [3] göstermektedir.

\subsection{Kütle Kaybı Sonuçları}

Saf ve pirina katkılı bağlayıcıların, sıcaklık ve havanın etkisiyle bünyelerinde meydana gelen uçucu madde kaybı veya yaşlanması RTFOT ile belirlenmiștir. Pirina katkı oranına bağlı olarak, bağlayıcıların kütle kaybı değerlerinde meydana gelen değişimler Şekil 9'da verilmiştir.

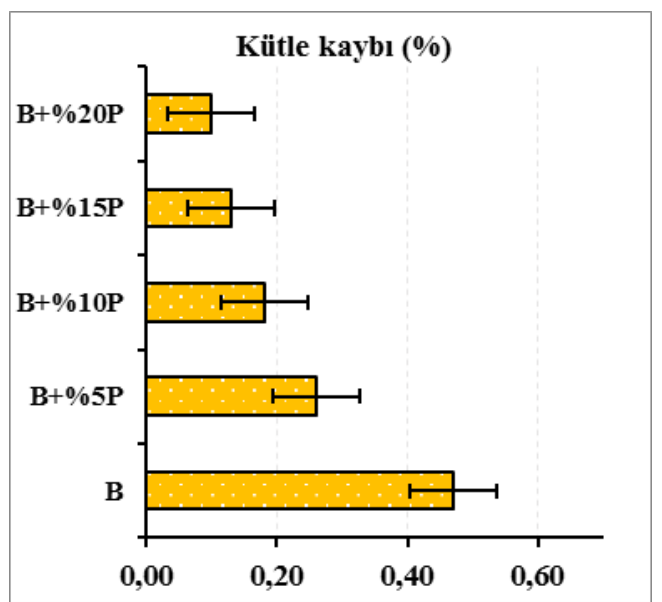

Şekil 9. Bağlayıcıların kütle kaybı değişimleri

Şekil 9'da saf ve pirina katkılı bağlayıcıların, bünyesinde oluşan kütle kayıpları şartnamenin öngördügü sınırın (maks. 1,0) oldukça altında kaldığı görülmektedir. Bu durum, pirina'nın bağlayıcıların yaşlanması veya sertleşmesi üzerinde olumsuz bir etkiye sahip olmadığı, bağlayıcıları yüksek sıcaklık ve oksidasyona karşı daha dirençli hale getirdiğini [3] göstermektedir.

\subsection{Bağlayıcıların Mikroyapısal Analiz Sonuçları}

Calıșmada, pirina katkısının bitümlü bağlayıcıların mikroyapısal yapısı üzerindeki etkileri SEM ve XRD analiz testleri ile belirlenmiștir. İlk olarak, pirina katkısının SEM görüntüsü ve XRD deseni Şekil 10'da verilmiștir. Pirina'nın bağlayıcılar üzerindeki etkisini değerlendirebilmek amacıyla, saf bitüm (B) ile 
DEÜ FMD 23(69), 1015-1025, 2021

bağlayıcı özelliklerini iyileştirmede kritik bir oran olan \%15 pirina katkılı bağlayıcının

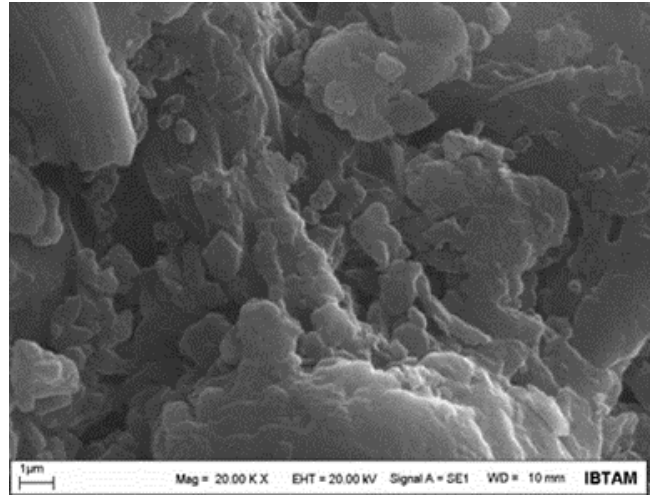

(a)
(B+\%15P) SEM görüntüleri ve XRD desenleri Şekil 11'de verilmiștir.

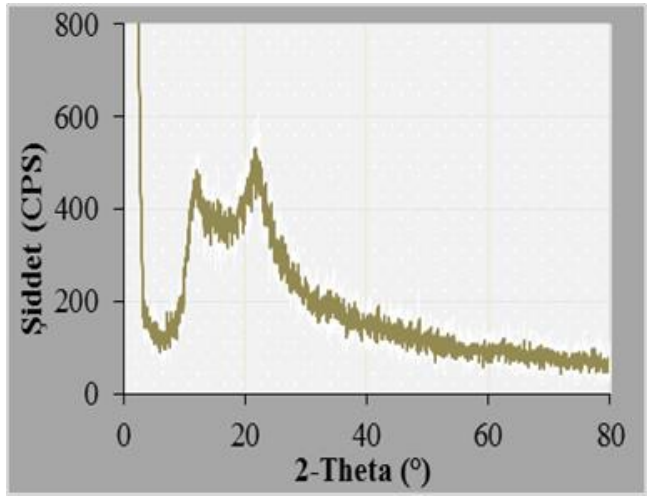

(b)

Şekil 10. Pirina'nın SEM görüntüsü (a), XRD deseni (b)
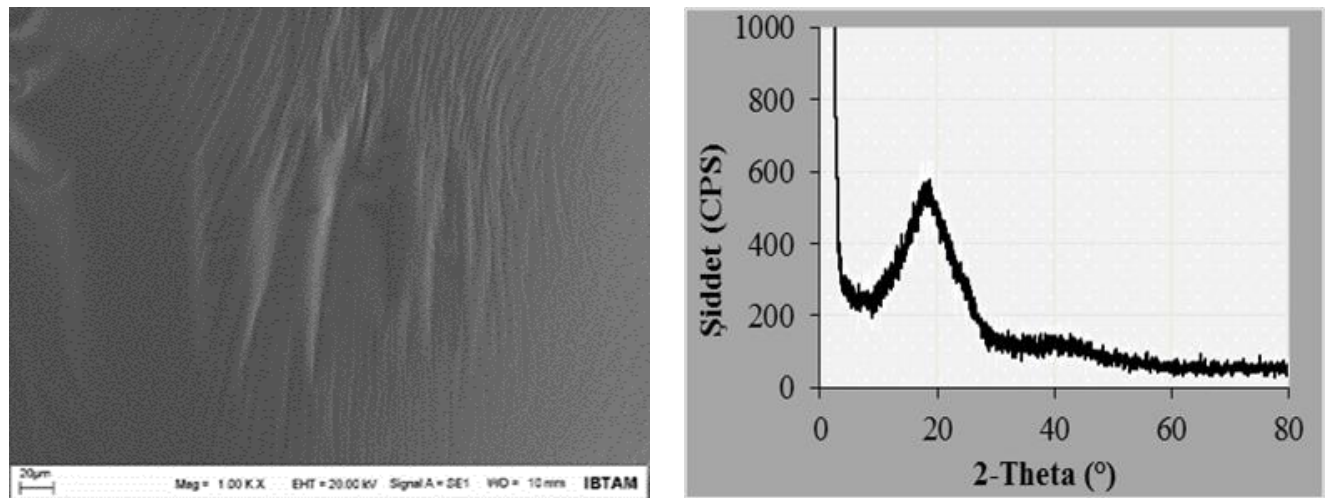

(a)
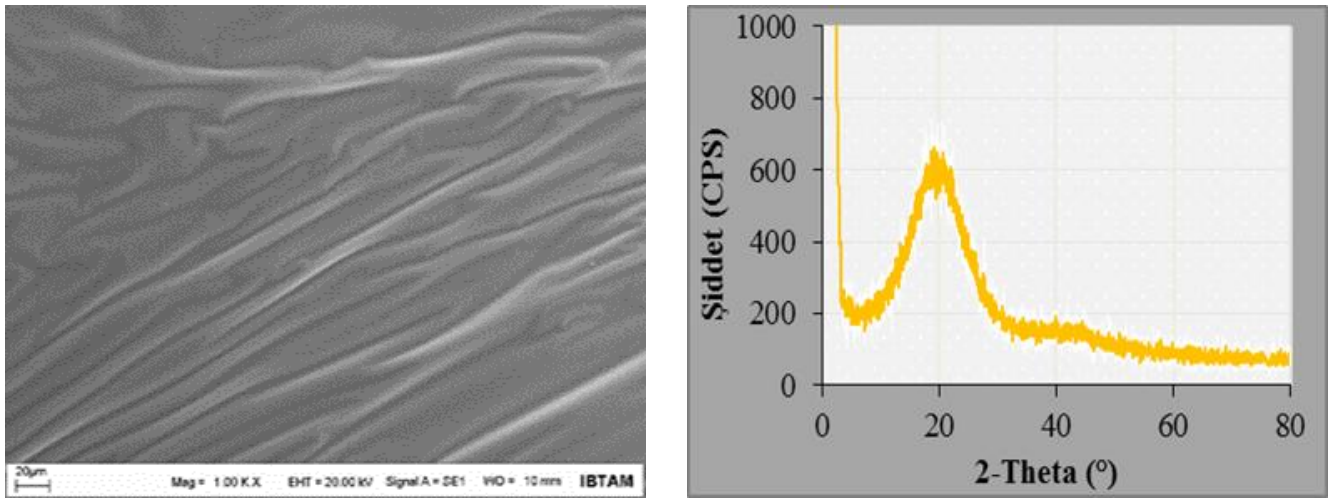

(b)

Şekil 11. Bağlayıcıların SEM görüntüleri ve XRD desenleri, B (a), B+\%15P (b) 
DEÜ FMD 23(69), 1015-1025, 2021

Sekil 10'da pirina'nın SEM ve XRD deseni incelendiğinde, selülozik yapıdaki pirina katkısının yapısının homojen ve farklı tane boyutlarından oluştuğu görülmektedir. Orijinal pirina katkısı bir biyokütlesel ürün olduğundan, yapıda gözeneklilik olmaması beklenen bir sonuçtur. Pirina katkısının XRD deseni incelendiğinde ise yarı-kristalin $\left(2 \theta \cong 13^{\circ}\right)$, kristalin $\left(2 \theta \cong 22^{\circ}\right)$ ve amorf $\left(2 \theta \cong 35^{\circ}\right)$ olmak üzere [35] üç farklı makromoleküler yapıdan oluştuğu görülmektedir.

Șekil 11a'da saf bitümün SEM görüntüsü incelendiğinde, yüzeysel yapıda hafif büzülmeler olduğu görülmektedir. Saf bitümün XRD deseni incelendiğinde iki makromoleküler yapının mevcut olduğu, bunlardan ilkinin $2 \theta \cong 20^{\circ}$ civarında bitümün karakteristik piki olduğu ve yapıdaki kristalliği gösterdiği, diğerinin ise $2 \theta \cong$ $40^{\circ}$ civarındaki geniș ve yayvan görülen amorf yapının olduğu görülmektedir. Şekil 11b'de \%15 pirina katkılı bağlayıcının SEM görüntüsü incelendiğinde ise pirina katkısıyla yüzeydeki büzülmelerin arttığı, ancak yine de karışımın homojen ve tek fazlı olduğu görülmektedir. Nitekim bu büzülmeleri, bağlayıcının XRD deseninde $2 \theta \cong 20^{\circ}$ civarındaki kristalin pikinde meydana gelen artıș ve $20 \cong 40^{\circ}$ civarındaki amorfluğun daha da belirginleșmesi doğrulamaktadır.

Sonuç olarak, bitüm-pirina karıșımının homojen tek fazlı bir yapı gibi davrandığı, pirina'nın bitümün sertleşmesi üzerinde etkili olduğu ancak bununla beraber selülozik yapısı sebebiyle aynı zamanda karıșımın esnek bir davranıș sergilemesine neden olduğu ifade edilebilir.

\section{Sonuçlar}

$\mathrm{Bu}$ çalışmada, biyokütlesel bir atık olan pirina'nın bitümün fiziksel ve mikroyapısal özellikleri üzerindeki etkisi araștırılmış ve aşağıdaki sonuçlar elde edilmiştir.

1. Penetrasyon deneyi sonuçlarına göre, pirina oranının artıșı ile modifiye bağlayıcıların \%15 oranına kadar sertleștiği, daha sonra yumușamaya bașladığı görülmüștür.

2. Yumuşama noktası deney değerlendirildiğinde, penetrasyon sonuçları ile uyumlu olduğu ve \%15 oranına kadar yumuşama noktası değerlerinin artış gösterdiği yani bağlayıcının sertleștiği, bu orandan sonra yumuşama noktası

\begin{abstract}
değerlerinin azalmaya başladığı görülmüştür. Penetrasyon ve yumuşama noktası sonuçları birlikte değerlendirildiğinde, \%15 pirina katkılı bağlayıcıların yüksek sıcaklardaki deformasyon direncinin arttığı ve bu bölgelerde kullanılabileceğini göstermektedir.
\end{abstract}

3. Düktilite deney sonuçlarına göre, bağlayıcıların uzama yeteneği ve kohezyonu üzerinde pirina katkısının olumlu bir etkiye sahip olduğu görülmüştür.

4. PI sonuçlarına göre, pirina katkısının bağlayıcıların sıcaklık hassasiyetinin azalması yönünde olumlu bir etkiye sahip olduğu ve böylece pirina katkılı bitümlerin yüksek sıcaklığa sahip bölgelerde kullanılabileceği ifade edilebilir.

5. RTFOT sonuçlarına göre, pirina katkısının bağlayıcıların yüksek sıcaklık ve oksidasyon direnci üzerinde olumlu bir etkiye sahip olduğu görülmüștür.

6. Saf ve pirina katkılı bağlayıcıların SEM ve XRD analiz sonuçları birlikte değerlendirildiğinde, pirina-bitüm karışımının homojen ve tek fazlı bir yapıda olduğu görülmüştür.

Sonuç olarak, biyokütlesel bir tarım atığı olan pirina'nın bitümün fiziksel ve mikroyapısal özellikleri üzerinde iyileştirici bir etkiye sahip olduğu görülmüștür. Ayrıca, pirina'nın karayolu mühendisliğinde bir iyileștirici olarak kullanılmasının, tarımsal atıkların çevreye vermiş olduğu zararı azaltacağı ve ekonomiye önemli bir katkı sağlayabileceği düșünülmektedir.

\section{Teşekkür}

$\mathrm{Bu}$ çalışmada, İnönü Üniversitesi Kimya Mühendisliği bölümü öğretim üyesi Doç. Dr. Yunus ÖNAL'a, kimyasal deneyler ve bunların yorumlanmasına olan katkılarından dolayı teşekkür ederiz.

\section{Kaynakça}

[1] Lavin, P.G. 2003. Asphalt Pavements, Spon Press, London and New York.

[2] Ameri, M., Mansourian, A., Ashani, S.S., Yadollahi, G. 2011. Technical study on the Iranian Gilsonite as an additive for modification of asphalt binders used in pavement construction, Construction and Building Materials, Cilt. 25, s. 1379-1387. DOI: 10.1016/j.conbuildmat.2010.09.005

[3] Geçkil, T., Seloğlu, M. 2018. Performance properties of asphalt modified with reactive terpolymer, 
DEÜ FMD 23(69), 1015-1025, 2021

Construction and Building Materials, Cilt. 173, s. 262-271. DOI: 10.1016/j.conbuildmat.2018.04.036

[4] Geçkil, T., Önal, Y., İnce, C.B. 2021. Atık PET ile modifiye edilmis bitümlü sıcak karıșımların nem direnci, Politeknik Dergisi, Cilt. 24, s. 461-471. DOI: 10.2339/politeknik.699662

[5] Ahmedzade, P., Fainleib, A., Günay, T., Grygoryeva, 0. 2014. Modification of bitumen by electron beam irradiated recycled low density polyethylene, Construction and Building Materials, Cilt. 69, s. 1-9. DOI: 10.1016/j.conbuildmat.2014.07.027

[6] Masad, E., Huang, C.W., Airey, G., Muliana, A. 2008 Nonlinear viscoelastic analysis of unaged and aged asphalt binders, Construction and Building Materials, Cilt. 22(11), s. 2170-2179. DOI 10.1016/j.conbuildmat.2007.08.012

[7] Airey, G.D. 2002. Rheological evaluation of ethylene vinyl acetate polymer modified bitumens, Construction and Building Materials, Cilt. 16(8), s. 473-487. DOI: 10.1016/S0950-0618(02)00103-4

[8] Geçkil, T. 2019. Physical, Chemical, Microstructura and Rheological Properties of Reactive TerpolymerModified Bitumen, Materials, Cilt. 12, s. 921. DOI 10.3390/ma12060921

[9] Tunç, A. 2007. Yol Malzemeleri ve Uygulamaları, Nobel Yayın Dağıtım, Ankara.

[10] Garcia-Morales, M., Partal, P., Navarro, F.J., Gallegos, C. 2006. Effect of waste polymer addition on the rheology of modified bitumen, Fuel, Cilt. 85(7-8), s. 936-943. DOI: 10.1016/j.fuel.2005.09.015

[11] Ismail, Z.Z., AL-Hashmi, E.A. 2008. Use of waste plastic in concrete mixture as aggregate replacement, Waste Management, Cilt. 28(11), s. 2041-2047. DOI: $10.1016 /$ j.wasman.2007.08.023

[12] Ozturk, M., Saba, N., Altay, V., Iqbal, R., Hakeem, R.K. Jawaid, M., Ibrahim, F.H. 2017. Biomass and bioenergy: An overview of the development potential in Turkey and Malaysia, Renewable and Sustainable Energy Reviews, Cilt. 79, s. 1285-1302. DOI: 10.1016/j.rser.2017.05.111

[13] Main-Knorn, M., Cohen, W.B., Kennedy, R.E., Grodzki, W., Pflugmacher, D., Griffiths, P., Hostert, P. 2013 Monitoring coniferous forest biomass change using a Landsat trajectory-based approach, Remote Sensing of Environment, Cilt. 139, s. 277-290. DOI: 10.1016/j.rse.2013.08.010

[14] Nansaior, A., Patanothai, A., Rambo, A.T., Simaraks, S 2013. The sustainability of biomass energy acquisition by households in urbanizing communities in Northeast Thailand, Biomass and Bioenergy, Cilt. 52, s. 113-121. DOI: 10.1016/j.biombioe.2013.03.011

[15] McKendry, P., 2002. Energy production from biomass (part 2): conversion Technologies, Bioresource Technology, Cilt. 83, s. 47-54. DOI: 10.1016/S0960-8524(01)00119-5

[16] Goyal, H.B., Seal, D., Saxena, R.C. 2008. Bio-fuels from thermochemical conversion of renewable resources: A review, Renewable and Sustainable Energy Reviews, Cilt. 12, s. 504-517. DOI: 10.1016/j.rser.2006.07.014

[17] Demirbaș, A. 2001. Biomass resource facilities and biomass conversion processing for fuels and chemicals, Energy Conversion and Management, Cilt.
42 , s. $1357-1378$. DOI: $10.1016 /$ S01968904(00)00137-0

[18] Rios-Badran, I., Luzardo- Ocampo, I., Garcia-Trejo, J.F., Santos-Cruz, J., Gutierrez- Antonio, C. 2020. Production and characterization of fuel pellets from rice husk and wheat straw, Renewable Energy, Cilt. 145, s. 500-507. DOI: 10.1016/j.renene.2019.06.048

[19] Mahmudul Hasan, M.D., Hu, X., Gunawan, R., Li, C.Z. 2017. Pyrolysis of large mallee wood particles: Temperature gradients within a pyrolysing particle and effects of moisture content, Fuel Processing Technology, Cilt.158, s.163-171. DOI: 10.1016/j.fuproc.2016.12.018

[20] Jin, X., Chen-yang, N., Deng-yin, Z., Yan-hui, G., Qi-min, H., Yu-hong, X., Paul, B. 2019. Co-pyrolysis of rice straw and water hyacinth: Characterization of products, yields and biomass interaction effect, Biomass and Bioenergy, Cilt. 127, s. 105281. DOI: 10.1016/j.biombioe.2019.105281

[21] Liu, Z., Liu, X., Fei, B., Jiang, Z., Cai, Z., Yu, Y. 2013. The properties of pellets from mixing bamboo and rice straw, Renewable Energy, Cilt. 55, s. 1-5. DOI: 10.1016/j.renene.2012.12.014

[22] Obernberger, I., Thek, G. 2004. Physical characterisation and chemical composition of densified biomass fuels with regard to their combustion behaviour, Biomass and Bioenergy, Cilt. 27. $\quad$ s. 653-669. 10.1016/j.biombioe.2003.07.006

[23] Stelte, W., Holm, J.K., Sanadi, A.R., Barsberg, S., Ahrenfeldt, J., Henriksen, U.B. 2011. Fuel pellets from biomass: The importance of the pelletizing pressure and its dependency on the processing conditions, Fuel, Cilt. 90, s. 3285-3290. DOI: 10.1016/j.fuel.2011.05.011

[24] Kwoczynski, Z., Cmelík, J. 2021. Characterization of biomass wastes and its possibility of agriculture utilization due to biochar production by torrefaction process, Journal of Cleaner Production, Cilt. 280, s. 124302. DOI: $10.1016 /$ j.jclepro.2020.124302

[25] Usmani, Z., Sharma, M., Kumar Awasthi, A., Sivakumar, N., Lukk, T., Pecoraro, L., Kumar Thakur, V., Roberts, D., Newbold, J., Kumar Gupta, V. 2021. Bioprocessing of waste biomass for sustainable product development and minimizing environmental impact, Bioresource Technology, Cilt. 322, s. $124548 . \quad$ DOI: 10.1016/j.biortech.2020.124548

[26] Sansoucy R. 1985. Olive by-products for animal feed. FAO Animal Production and Health Paper 43, Rome, Italy.

[27] Filya, İ., Hanoğlu, H., Canbolat, Ö., Sucu, E. 2006. Kurutulmus Pirinanın Yem Değeri ve Kuzu Besisinde Kullanılma Olanakları Üzerinde Araştırmalar 2. Kuzuların Besi Performansı Üzerine Etkileri, Uludağ Üniversitesi Ziraat Fakültesi Dergisi, Cilt. 20(1), s. 13-23. DOI: http://hdl.handle.net/11452/3124

[28] Ticaret Bakanlığı. 2019. 2018 yılı zeytin ve zeytinyağ raporu, https://ticaret.gov.tr/data/5d41e59913b87639ac9 e02e8/3acedb62acea083bd15a9f1dfa551bcc.pdf (Erisim tarihi: 05.01.2021)

[29] Gök, O., Mesutoğlu, Ö.Ç. 2017. Ağır Metallerin Giderimi İçin Düșük Maliyetli Adsorban Olarak Pirina Kullanımı, Gazi Üniversitesi Mühendislik 
Mimarlık Fakültesi Dergisi, Cilt. 32(2), s. 507-516. DOI: 10.17341/gazimmfd.322176

[30] Öden, M.K., Şahinkaya, S., Küçükçongar, S. 2017. Colour Removal with Adsorption Process Using Pomace, Cumhuriyet Science Journal, Cilt. 38(4), s. 215-219. DOI: $10.17776 /$ csj.363686

[31] Aktas, A., Özer, S. 2014. Ham Pirina Yağının Biyodizel Potansiyelinin Araştırılması, Süleyman Demirel Üniversitesi Ziraat Fakültesi Dergisi, Cilt. 9(1), s. 132-139. DOI: ISSN 1304-9984

[32] Yaşdağ, T., Tekin, A. 2017. Ayçiçek Ve Pirina Yağlarının Kızartma Stabilitelerinin Karşılaștırılması, Gıda, Cilt. 42(2), s. 105-115. DOI: 10.15237/gida.GD16071

[33] Kıcı, G.Ö., Saltan, M. 2020. Pirinanın bitüm modifikasyonunda kullanımının araștırılması, Uluslararası Teknolojik Bilimler Dergisi, Cilt. 12(1), s. 1-9.

[34] Mazumder, M., Ahmed, R., Ali, A.W., Lee, S.J. 2018 SEM and ESEM techniques used for analysis of asphalt binder and mixture: A state of the art review Construction and Building Materials, Cilt. 186, s. 313329. DOI: 10.1016/j.conbuildmat.2018.07.126

[35] AlHumaidan F.S., Hauser, A., Rana, M.S., Lababidi, H.M.S., Behbehanii M. 2015. Changes in asphaltene structure during thermal cracking of residual oils: XRD study, Fuel, Cilt. 150, s. 558-564. DOI: 10.1016/j.fuel.2015.02.076

[36] Hou, Y., Wang, L., Wang, D., Guo, M., Liu, P., Yu, J. 2017. Characterization of Bitumen Micro-Mechanical Behaviors Using AFM, Phase Dynamics Theory and MD Simulation, Materials, Cilt. 10(2), s. 208. DOI: $10.3390 / \mathrm{ma} 10020208$

[37] Nivitha, M.R., Prasad, E., Krishnan, J.M. 2016. Ageing in modified bitumen using FTIR spectroscopy, International Journal of Pavement Engineering, Cilt 17(7), s. $\quad 565-577 . \quad$ DOI: $10.1080 / 10298436.2015 .1007230$ 